\title{
Commentary
}

\section{Narrative Agency in Hashtag Activism: The Case of \#BlackLivesMatter}

\author{
Guobin Yang ${ }^{1,2}$ \\ ${ }^{1}$ Annenberg School for Communication, University of Pennsylvania, Philadelphia, PA 19104, USA; \\ E-Mail: guobin.yang@asc.upenn.edu \\ ${ }^{2}$ Department of Sociology, University of Pennsylvania, Philadelphia, PA 19104, USA
}

Submitted: 27 February 2106 | Accepted: 25 March 2016 | Published: 11 August 2016

\begin{abstract}
Hashtag activism happens when large numbers of postings appear on social media under a common hashtagged word, phrase or sentence with a social or political claim. The temporal unfolding of these mutually connected postings in networked spaces gives them a narrative form and agency. Applying Karlyn Campbell's propositions about rhetorical agency to the case of \#BlackLivesMatter, this essay shows that narrative agency in hashtag activism derives from its narrative form as well as from its contents and social context. Narrative agency is communal, invented, skillful, and protean.
\end{abstract}

\section{Keywords}

\#BlackLivesMatter; agency; hashtag activism; narrative

\section{Issue}

This commentary is part of the issue "Political Agency in the Digital Age: Media, Participation and Democracy", edited by Anne Kaun (Södertörn University, Sweden), Maria Kyriakidou (University of East Anglia, UK) and Julie Uldam (Roskilde University, Denmark).

(C) 2016 by the author; licensee Cogitatio (Lisbon, Portugal). This article is licensed under a Creative Commons Attribution 4.0 International License (CC BY).

\section{Introduction}

One of the most interesting developments in digital activism in recent years is the rise of hashtag activism, meaning discursive protest on social media united through a hashtagged word, phrase or sentence. \#BlackLivesMatter, for example, was a protest movement that happened both in the streets and on social media in response to the acquittal of George Zimmerman in July 2013 in the shooting death of AfricanAmerican teen Trayvon Martin. Another example is \#Ferguson, which happened in response to the shooting to death of Michael Brown on August 9, 2014 by a police officer in Ferguson, Missouri. Within the first week of Brown's death, millions of posts with the hashtagged \#Ferguson appeared on Twitter alone (Bonila \& Rosa, 2015).

These important cases of online protest brought renewed attention to the power of digital activism in shaping public discourse. Research on digital activism has focused on its networked and connective character (Bennett \& Segerberg, 2013) and debated about the question of organization and leadership (Gerbaudo, 2012). This essay argues that a neglected form of agency in the study of digital activism is its narrative form.

\section{The Narrative Analysis of Social Movements}

Narrative forms are an essential element of human existence (Polkinghorne, 1988, p. 1). Scholars have argued that "the nature of daily action and self-construction lends an essentially narrative character to life" (Steinmetz, 1992, p.496). Carr, for example, claims that "Narrative is not merely a possibly successful way of describing events; its structure inheres in the events themselves" (1986, p. 117). Bruner (2004, p. 708) similarly states that "a life as led is inseparable from a life as told."

The most distinct feature of the narrative form is its temporal sequence. In literary representations, narrative form accounts for the progression from beginning through middle to an end. Thus Kenneth Burke states that a literary work has form "in so far as one part of it leads a reader to anticipate another part, to be gratified by the sequence" $(1968$, p. 124). The form of de- 
tective fiction, for example, often centers on a quest, adventure, or mystery. As the protagonist (the detective) goes in search of solutions, the plot generates curiosity, surprise, and suspense (Sternberg, 2003).

Like works of literature, social movements have narrative forms. In his study of working-class formation, sociologist Steinmetz notes that "Narrative thus has a beginning, a middle, and an end, and the movement toward the end is accounted for by conflicts, causal explanations, and the sequence of events" (Steinmetz, 1992, p. 497). Focusing on the rhetorical form of social movements, Griffin $(1952,1969,2003)$ and Cathcart (1978) underscore the processual nature of social movements. Cathcart (1978, p. 234) argues that movements are "a kind of ritual conflict whose most distinguishing form is confrontation." Griffin (1969, p. 461) maintains that all social movements have forms: "Every movement...has form....It is a progression...from suffering, misfortune, passive condition, state of mind."

Social movement scholars have long recognized the power of narratives (Polletta, 2006; Selbin, 2010), but the question of narrative agency has received relatively little attention in studies of digital activism (but see Clark, 2016; Kaun, 2015). In contrast to "traditional" forms of digital activism such as distributed denial-ofservice actions (DDoS) or signing online petitions, hashtag activism has a distinctly narrative character. An incidence of hashtag activism takes place when large numbers of comments and retweets appear on social media in response to a hashtagged word, phrase, or sentence. Because these comments and retweets consist of numerous personal stories and appear in temporal order, they assume a narrative form. Narrative agency is thus central to hashtag activism.

Rhetorical theorist Karlyn Campbell defines rhetorical agency as "the capacity to act, that is, to have the competence to speak or write in a way that will be recognized or heeded by others in one's community" (Campbell, 2005, p. 3). Adapting this definition, I consider narrative agency in hashtag activism as the capacity to create stories on social media by using hashtags in a way that is collective and recognized by the public. Illustrated with an analysis of a historical text (a speech allegedly delivered by Sojourner Truth at the 1851 woman's rights convention in Akron, Ohio), Campbell's five propositions about rhetorical agency are useful for analyzing narrative agency in hashtag activism.

First, she argues that "agency is communal, social, cooperative, and participatory and, simultaneously, constituted and constrained by the material and symbolic elements of context and culture" (p. 3). Second, agency is both "invented" and invention. Because authors and rhetors "are materially limited, linguistically constrained, historically situated subjects" (p. 5), they have to find and invent ways of expression. Agency is thus invention. Third, agency emerges in artistry or craft. It is a set of heuristic skills and includes "strata- gem, flair, subtlety, and the like as well as the habits of mind learned through practice" (p. 7)

Fourth, agency is achieved through form. The agency of form is realized through generic conventions and textual and rhetorical devices. Narrative forms have agency because they "invite" audiences, readers or listeners to participate in the co-production of stories (also see Polletta, 2006). As Campbell puts it, "Textual agency is linked to audiences and begins with the signals that guide the process of "uptake" for readers or listeners enabling them to categorize, to understand how a symbolic act is to be framed" (Campbell, 2005, p. 7).

Fifth, Campbell warns that "agency can be malign, divisive, and destructive" (2005, p. 7). It is "protean, ambiguous, open to reversal" (p. 1). The openness of the narrative form makes it susceptible to perversion.

Below, I will discuss each of these five propositions as they are applied to the analysis of \#BlackLivesMatter. One modification I will make to Campbell's framework is that I consider form as the most fundamental feature of the narrative agency of digital activism and will discuss it first.

\section{The Power of Narrative Form}

Digital activism on social media has different narrative forms because narrative conventions may differ from platform to platform. Earlier digital protests, for example, took place in electronic bulletin boards or newsgroups (Gurak, 1999), which allowed the posting and cross-positing of longer narratives. The wide circulation of several such narratives could create an online protest event, but the number of participating voices may be significantly more limited than on Twitter. A unique feature of hashtag activism on Twitter is that it starts, well, with a hashtag. Adding the hashtag sign \# to a word, such as \#change or \#climate, makes it easier for other users on Twitter to search, link, and interact with one another via the hashtagged word and to share stories related to it. Indeed, such hashtags are a common practice on Twitter. They are routine hashtags.

These everyday hashtags, however, do not usually evolve into contentious collective events online. The most influential cases of hashtag activism, as opposed to routine hashtags, have a recognizable narrative form with a beginning, a crisis/conflict, and an end (Clark, 2016). Within this temporal framework, individuals contribute to the co-production of narratives by hashtagging their personal thoughts, emotions, and stories.

The hashtags in many influential cases of hashtag activism have complete sentence structures rather than single words like \#change. The following is a random list of examples: \#BlackLivesMatter, \#BringBackOurGirls, \#StopGamerGate, \#WhylStayed, \#JeNeSuisPasCharlie, \#OccupyEverywhere, \#CancelColbert, \#ThisIsACoup, \#lcantBreathe, \#MuslimsAreNotTerrorist.

As the above examples show, these hashtags con- 
tain verbs expressing a strong sense of action and force. The actions are petitioning, demanding, appealing, and protesting. They express refusals, objections, and imperatives to take immediate action. They often challenge narratives in mainstream media. In all these ways, activist hashtags embody what Cathcart (1978, p. 234), in his rhetorical study of social movement forms, refers to as "a kind of ritual conflict whose most distinguishing form is confrontation."

The narrative forms of hashtag activism are not limited to the syntactical structures of the hashtags. They also consist of the generic conventions and rhetorical devices used in the hashtagged postings. An incidence of hashtag activism typically spans days, weeks, and even months. During this period, textual signals and rhetorical devices "guide the process of 'uptake' for readers or listeners enabling them to categorize, to understand how a symbolic act is to be framed." (Campbell, 2005, p.7) They encourage audience participation. People participate by reading, retweeting, commenting on others' tweets or posting their own with the same hashtag. The temporal unfolding of such an incident is a process of people interacting with one another and collectively creating a larger narrative. To understand the narrative agency in this process, I will now turn to the other four dimensions of narrative agency as outlined by Karlyn Campbell and use the example of \#BlackLivesMatter as an illustration.

\section{Communal, Invented, Skillful, and Protean}

According to a USA Today story (Guynn, 2015), the statement "Black lives matter" initially appeared in a Facebook post by Alicia Garza in July 2013 after Garza saw from television news the acquittal of George Zimmerman in the shooting death of African-American teen Trayvon Martin. Garza's friend Patrisse Cullors added the hashtag sign to the statement after she read it. The rest is history. \#BlackLivesMatter quickly spread on social media and spawned not only an online protest event, but also a social movement organization headed by none other than Garza and Cullors.

At 8:45am Eastern Time on February 25, 2016, I searched the \#BlackLivesMatter hashtag using my personal Twitter account. As I scrolled down the screen, the results expanded. I saved a 74-page pdf document of the search results. These 74 pages are only a small slice of the much longer temporality of the \#BlackLivesMatter, but still show clearly \#BlackLivesMatter as a case of narrative agency.

My Twitter's search results are shown in reverse chronological order, with the most recent postings at the top. The 74-page document is thus a narrative in reverse chronological order. My experience of reading it was like reading a live narrative about an unfolding event, one that is at the same time created by the narrative form.
At the top of the search results was a HuffPost Politics story showing a photograph of Hillary Clinton making a speech. The title of the story is "Black Lives Matter Activists Interrupt Hillary Clinton At Private Event In South Carolina: They wanted her to account for some of her past statements on racial justice." As I scroll down the results, I begin to see the key aspects of narrative agency at work.

First, the communal and participatory feature of agency is evident from the many likes and retweets of individual postings. Some postings have hundreds of "favorites" and "retweets." Individuals in these communal spaces may or may not know one another. They are like dramatic personae in what Campbell refers to, citing Sartre, as "a serial relationship": "Individuals in a serial relationship have no set of attributes in common except their shared relationship to an external object, event, or, in other cases, to a law, an institution, a norm, a stereotype and so on." (Campbell, 2005, p. 4) In this case, since they all tweeted with the \#BlackLivesMatter hashtag, their relationship is primarily to the hashtag with all its moral, political, and social implications.

As I read on, the story grows, expands, and becomes richer and more complex. Texts are mixed with photos. One hashtag is used in combination with another, such that \#BlackLivesMatter becomes intertwined with multiple other hashtags. Again, in reverse chronological order, I saw the following hashtags used together with \#BlackLivesMatter: \#blackish, \#WhichHillary, \#notasuperpredator, \#ChicagoPD, \#alwaysshavealwayswill, \#Apple, \#FeeltheBern, \#Trump, \#abff, \#blacktwitter, \#OscaSoWhite, and so on and so forth. Each of these hashtags tells a new story, but all are linked to \#BlackLivesMatter. \#BlackLivesMatter becomes a unifying theme of multiple stories about racial justice.

Second, Campbell writes that agency is invention and authors and rhetors are "inventors" in the rhetorical sense. They "link past and present, and find means to express those strata that connect the psyche, society, and world, the forms of feeling that encapsulate moments in time" (p. 5). This process of invention depends on artistry, craft, stratagem, flair, subtlety, and skill.

\#BlackLivesMatter is the result of such a process of skillful invention. In a simple sense, all Twitter postings have to have some degree of artistry in order to meet the 140-character exigency of the Twitter platform. To create a collective story of struggles for racial justice, such as through \#BlackLivesMatter, requires individual users to mobilize additional artistry and flair. One particularly powerful method is the sharing of personal stories. For example, one posting on February 22 goes: “In 2015, dozens of African American's [sic] were killed by police. I put 84 of their names on my shirt. \#BlackLivesMatter pic.twitter.com/cOHOltrgEO." Such personal stories are linked to broader social issues and shared with the public through the use of the hashtag, thus 
giving hashtag activism a communal and collective character.

Part of the artistry of a collective hashtag narrative derives from its versatility of expressive forms. Besides the common practices of tweeting and retweeting, the posting itself takes different forms. There are photographs, jokes, slogans, curses, and cartoons. There are links to news, videos, music and songs. In the middle of these personalized but artful story-telling, a protest narrative is created and carried forward.

Finally, as Campbell notes, rhetorical agency is protean and promiscuous with a "malign, divisive, and destructive" side. In the case of \#BlackLivesMatter, this malign side is seen in the racist language and remarks that appear in my search results. Considering the open nature of the Twitter platform, this is not surprising. The presence of such racist remarks vindicates the urgency of struggles for racial justice and the challenges facing activists and citizens. To those involved in the online narrating of \#BlackLivesMatter, they are concrete evidence of the necessity of taking personal action. Thus, in response to a racist posting, one person tweeted on February 16: "I support \#BlackLivesMatter because there's people like this."

\section{The Social Context of Narrative Form}

In Campbell's study of rhetorical agency, the capacity to act is "constituted and constrained by the material and symbolic elements of context and culture" (p. 3). In other words, agency responds to social conditions and articulates social issues. In the same way, the narrative forms of hashtag activism are not independent of culture and society. It is not a coincidence that hashtag activism has been especially notable in recent struggles for racial justice and gender equality (Berridge \& Portwood-Stacer, 2015; Clark, 2016). As Bonnia and Rosa (2015, p. 8) write in their study of \#Ferguson, "it is important to examine how and why digital activism has become salient to particular populations. It is surely not coincidental that the groups most likely to experience police brutality, to have their protests disparaged as acts of 'rioting' or 'looting,' and to be misrepresented in the media are precisely those turning to digital activism at the highest rates."

Because hashtag activism happens in social and political context, its forms may vary when contexts change. For example, does it take different narrative forms in a different language, say \#JeNeSuisPasCharlie in French? Are confrontational forms more prevalent in the U.S than in China? Are some forms more effective than others? These are some of the questions for future research.

\section{Acknowledgments}

I would like to thank Anne Kaun, Maria Kyriakidou, and
Julie Uldam for inviting me to give a keynote speech at the conference on "Political Agency in the Digital Age: Media, Participation and Democracy" in October 2015, which inspired this essay.

\section{Conflict of Interests}

The author declares no conflict of interests.

\section{References}

Bennett, P. W. L., \& Segerberg, D. A. (2013). The logic of connective action: Digital media and the personalization of contentious politics. Cambridge: Cambridge University Press.

Berridge, S., \& Portwood-Stacer, L. (2015). Introduction: Feminism, hashtags and violence against women and girls. Feminist Media Studies, 15(2), 341-341. doi:10.1080/14680777.2015.1008743

Bonilla, Y., \& Rosa, J. (2015). \#Ferguson: Digital protest, hashtag ethnography, and the racial politics of social media in the United States. American Ethnologist, 42(1), 4-17. doi:10.1111/amet.12112

Bruner, J. (2004). Life as narrative. Social Research, 71(3), 691-710.

Burke, K. (1968). Counter-statement. Berkeley: University of California Press.

Campbell, K. K. (2005). Agency: Promiscuous and protean. Communication and Critical/Cultural Studies, 2(1), 1-19. doi:10.1080/1479142042000332134

Carr, D. (1986). Narratives and the real world. History and Theory, 25, 117-131.

Cathcart, R. (1978). Movements: Confrontation as rhetorical form. Southern Speech Journal, 43, 233-247.

Clark, R. (2016). "Hope in a hashtag": The discursive activism of \#WhylStayed. Feminist Media Studies. doi:10.1080/14680777.2016.1138235

Gerbaudo, P. (2012). Tweets and the streets: Social media and contemporary activism. London: Pluto Press.

Griffin, L. M. (1952). The rhetoric of historical movements. Quarterly Journal of Speech, 38, 184-188.

Griffin, L. M. (1969). A dramatistic theory of the rhetoric of movements. In W. H. Rueckert (Ed.), Critical responses to Kenneth Burke (pp. 456-477). Minneapolis: University of Minnesota Press.

Griffin, C. J. G. (2003). Movement as memory: Significant form in eyes on the prize. Communication Studies, 54(2), 196-210.

Gurak, L. J. (1999). Persuasion and privacy in cyberspace: The online protests over lotus marketplace and the clipper chip (Revised edition). New Haven: Yale University Press.

Guynn, J. (2015, March 4). Meet the woman who coined \#BlackLivesMatter. Retrieved from http://www.usa today.com/story/tech/2015/03/04/alicia-garza-black -lives-matter/24341593

Kaun, A. (2015). When narratives travel: The Occupy 
Movement in Latvia and Sweden. In J. Uldam \& A. Vestergaard (Eds.), Civic engagement and social media (pp. 111-130). London: Palgrave Macmillan UK. Retrieved from http://link.springer.com/chapter/10. 1057/9781137434166_6

Polkinghorne, D. (1988). Narrative knowing and the human sciences. Albany: State University of New York Press.

Polletta, F. (2006). It was like a fever: Storytelling in pro- test and politics. Chicago: University of Chicago Press. Selbin, E. (2010). Revolution, rebellion, resistance: The power of story. London and New York: Zed Books.

Steinmetz, G. (1992). Reflections on the role of social narratives in working-class formation: Narrative theory in the social sciences. Social Science History, 16(3), 489-516.

Sternberg, M. (2003). Universals of narrative and their cognitivist fortunes. Poetics Today, 24(2), 297-395.

\section{About the Author}

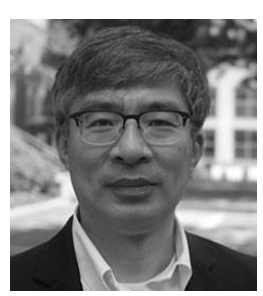

Guobin Yang is an Associate Professor of Communication and Sociology at the Annenberg School for Communication and Department of Sociology at the University of Pennsylvania. For more information, please see https://www.asc.upenn.edu/people/faculty/guobin-yang-phd 